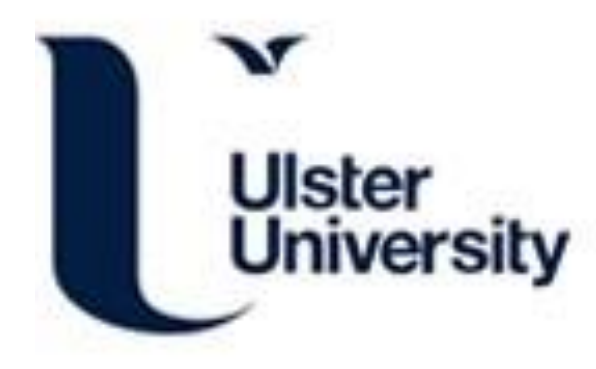

\title{
Exploring Visualization of Complex Telecommunications Systems Network Data
}

Myers, M., Sterritt, R., Curran, E., \& Song, H. (2002). Exploring Visualization of Complex Telecommunications Systems Network Data. In Unknown Host Publication IEEE. https://doi.org/10.1109/ICSMC.2002.1175708

Link to publication record in Ulster University Research Portal

\author{
Published in: \\ Unknown Host Publication
}

Publication Status:

Published (in print/issue): 01/10/2002

DOI:

10.1109/ICSMC.2002.1175708

\section{Document Version}

Publisher's PDF, also known as Version of record

\section{General rights}

Copyright for the publications made accessible via Ulster University's Research Portal is retained by the author(s) and / or other copyright owners and it is a condition of accessing these publications that users recognise and abide by the legal requirements associated with these rights.

\section{Take down policy}

The Research Portal is Ulster University's institutional repository that provides access to Ulster's research outputs. Every effort has been made to ensure that content in the Research Portal does not infringe any person's rights, or applicable UK laws. If you discover content in the Research Portal that you believe breaches copyright or violates any law, please contact pure-support@ulster.ac.uk. 


\title{
Exploring Visualization of Complex Telecommunications Systems Network Data
}

\author{
Michelle Myers, Roy Sterritt, Edwin P. Curran, Hongzhi Song \\ School of Information and Software Engineering, Faculty of Informatics, University of Ulster \\ Jordanstown, Newtownabbey, Northern Ireland, BT37 0QB, UK \\ \{r.sterritt, ep.curran, gh.song\}@ulster.ac.uk
}

\begin{abstract}
High-speed broadband telecomimnnication systems are built with extensive redandancy and complex management systems to ensure robostmess. The presence of a fanlt may be detected by the offending component, it parent component or by other components. This can potentially result in a net effect of a large number of alarm events being raised. There can be a considerable amount of alarma depending on the size and configarationo $f$ the network Data visualization can reduce monntains of date to visually insightful representations, which can ald decision-malding and identification of faults. This paper explores data visualizations to provide a contextt o assisti n the identification of such faults.
\end{abstract}

Keywords:D ata Visualization, Telecommunications, Complex Systems, Human-Machine Systen

\section{INTRODUCTION}

Robustness is a key feature and requirement of high-speed telecommunications systems. Networks are designed and managed with extensive redundancy to ensure this robustness and maintain a high Quality of Service (QOS)

Faults are rare within well managed networks but when they do occur the nature of the complexity, size and indeed the fact of the extensive in-built redundancy results in the appearance of a non-deterministic system.

The high-speed network system under investigation in this research is the Synchronous Digital Hierarchy (SDH). With the Internet revolution the type of system becomes less importantas the traditional Telcos and Data Communications companies converge and adapt their current systems (such as IP over SDH) to fit the new and emerging realities of the Internet. However the management issues are generic in terms of QOS, robustnessa nd dealing with complexity and uncertainty under fault conditions.

Within Network Management, Fault Management is specifically concerned with the detection, isolation and correction of failures that effect availability of resources.

In the SDH world, Network Elements (NEs) raise alarm events which arec ascaded to theE lement Controller (EC) upon determining abnomal behavior. This can result in a lange number of alarm events being raised for any instance of a fault. In effectt hese alarms represents ymptoms of the fault or multiple faults and can result in the eventl og growing into a data mountain.

Fault management is an important but difficult area of telecommunications network management. Networks produce large amounts of alarm informationt hat must be analyzed and interrupted before the faults can be located [1] Alarm correlation is the central technique in fault identification [2] and in a network context is subject to uncertainty in its behavior.

Data Visualization is a powerful tool in modem computing. Ita lows ease of navigation of large information spaces and it is invaluable in communicating complex ideas. As the volume of data stored by organisations continues to increase, Data Visualization can reduce mountains of data to visually insightful representations, whichc ana idd ecisionm aking increase productivity, and in some cases reduce physical risk. As a result it is envisaged that the next generation of databases willb e more graphical and hence easier to navigate and accessible to a widerr ange of users. Such development isp ossible because of the increasesi $n$ computer processing power and screen resolution. Developers are starting to utilise the remarkable perceptual abilities that humans possess, such as thec apacity to recognise images quickly, and detect the subtlest changes in size, color, shape, movemento $\mathrm{r}$ texture [1].

As such this paper describes a prototype tool that was developed to exploreh ow to maximiset hep resentation of network management data underm etwork fault conditions to the operator. This is carried out in terms of overall context of network, viewing event pattems and results from data mining to assist in the quick identification of faults by utilising the perceptual abilities of the experienced operator as opposed to trawling through the individual events to establish the fault.

\section{VISUALIZATION AND} FAULT MANAGEMENT DATA

The trend in faultm anagetnenta nd indeed faulti dentification is towards automation; but there is reluctance in the telecommunications industry to utilize Artificial Intelligence techniques that may achieve this, directly in the fault management system. Utilizing visualization not only aims to assist the operator come to a quicker decision but may help with building confidence in the data mining process as well as capturing experts krowledge in terms of patterns that could be utilized to automatically identify the fault

\section{A. Visualization}

Visualization has become increasingly important to complex systems as they continue to produce large quantities of data. 
As the volume of data increases, the Visualization of data has become the most practicalm ethod of understanding the data.

Over the past few years, the use of visualization for aiding the analysis of data has greatly increased. From its initial role as simply a tool for presenting results, it has developed into a valuable tool for understanding data. The most common types of data produced by the modelling of physical systems are three-dimensional [3]. Visualization is concerned with exploring the data and information graphically in order to gain understanding and insight into data

\section{B. Visualization Technologies}

There are many visualization development tools available increasingly used techniques for 3D representations are Java 3D and VRML. The Java 3D API can be used to develop programmed applications and applets that model, animate, simulate and view 3D content. VRML development programs and VRML viewers can be easily implemented using the Java 3D API. VRML is ideal for encapsulating 3D content created by sophisticated modeling and animation authoring tools.

All oft he dynamics incorporated into the virtual worlds use interpolators. The VRML and the Java 3D API both provide interpolators for a number of functions for manipulating transformations within a transform group. They are used in modifying the values of a Switch node, and for modifying Material attributes such as color and transparency. These work well for simple changes to parts of scenes, but cannot be used for more complex behavior. This very simple form of programming does not cover the dynamics that are required for this visualization - namely the dynamic nature of alarm events arriving at then etwork manager in real-time. Such behavior could perhaps be incorporated into the scene via scripting, although this would depend on the details of the scripting language supported by the browser.

\section{Visualization used in Data Mining}

Data mining deals with the discovery of hidden knowledge, unexpected patterns and new rules for large databases. It may be proposed that a flaw in data mining is that it is not usercentred. It would be helpfult o visualize the data at all stages to enable the user to gain trust in the process and hence have more confidence in the mined patterns. The transformation from data to knowledge requires interpretation and evaluation, which also stands to benefit from multi-stage visualization of thep rocess. Usually visualization of data mining is typically used for the navigation of large volumes of data or interpreting the actual results, i.e. not the complete knowledge discovery process. Visualization techniques are a very useful method of discovering patterns in data sets, and may be used at the beginning of the data mining process to get a rough idea of the quality of the data set and where patterns are to be found. A growing research area is VRDM, where data mined results arep resented in a virtual reality world in real time [4-5].

\section{Data Mining Telecommunications Network Dato}

High-speed broadband telecommunication systems are built with extensive redundancy and complex management systems to ensure robustness [6]. The presence of a fault may be detected by the offending component, its parent component or by other components. This can potentially result in a net effect of a large number of alarm events being raised Data mining aims at the discoveryo $f$ interesting irregularities or exceptions from vast amounts of data, and as such could greatly assist in this area. Failures in the network are unavoidable, but quick detection and identification of faults is essential to ensure robustness. To this end the ability to correlate alarm events becomes very important.

\section{E. Visualization Applied to Telecommunications}

Within the telecommunications industry the Synchronous Digital Hierarchy (SDH) is an operational standard for broadband networks, offering increased bandwidth and sophisticated services. One key area of interest to engineers is the management of events and faults in a network of SDH multiplexers. An event is a change of status within a network that produces a corresponding alarm message or fault.

Fault Management is a critical, but a difficult area of telecommunications network management, since networks produce a vast quantity of data that must be analysed and interpreted before faults can be located. Alarm correlation is a central technique in fault identification yet it is difficult to cope with incomplete dats and the sheer complexity involved.

A 2D solution is often used where a network element within a topology is displayed on a location map [7]. Its colore ode indicates its faultc ondition, clicking on the element reveals a textl isto $f$ the alarm events.

Research into Visualization of telecommunications and network systems includes $[8,9,10,11]$.

\section{THE VISUALIZATION TOOL}

The management of faults is complex because;

- the occurrence of the fault is time variant and nondeterministic,

- faults can produce a cascade of other faults,

- fault handling mustb e performed in real-time.

The problem is compounded by the growth of networks and the increasing variety of network topologies.

\section{A. Requirements summany}

A summary of the requirements are;

1. A three dimensional view is required which reflects the currents tate of the network.

2. The Topology View should allow navigation of all network elements.

3. A Global View is required, which lists all thea larms present on the network. 
4. Users should be able to select an element within the topology view forc losers tudy, and receive information on alla larms present, for that particular element.

5. Users should be able to return to theT opology view, from any of the other Views.

6. The user should have access to all available network topology views.

7. Users should be able to view combined historical alarm data. That is, corresponding events - alarms 'present' and 'cleared'.

\section{B. Requirements Discussion}

The network topology view wast o be displayed in a threedimensional visualization. The network topology would show each element, in a color corresponding to the severity oft he alarms occurring on that element. Since there can be many alarms occurring on each element, and these alarms may have a different severityr ating, the greatest severity alarm color would be displayed.

When the user selects one of the networke lements, they should receive a local view, which lists the alarms occurring on that particular element.

When the user selects the network controller, they should receive a global view, which shows all of the alarms occurring on the whole network.

The system will also utilize other existing visualization tools, for instance a Gantt chart and a BBN view.

\section{1) Gantt Chant}

This tool allows visualization and navigation of extensive telecommunications data, specifically the event log from the element controller.' The Stimuli Event Correlation Analyser (NxGantt) displays the usera ctions against the alarm data in an easy to read color coded 'Gantt Chart' (Figure 1). This provides a much easier means to obtain a better picture of an individual alarms life span and how it fits in with other events. Figure 2 (a) and (b) shows how you can provide a context view. (c) and (d) demonstrates an prototype of the Gantt in VRML yet it does not necessarily provide as meaningfula view as the $2 \mathrm{D} \mathrm{Nx}$ Gantt.

2) $B B N$

Bayesian Belief Networks [12] are a tochnique used for representing and reasoning with uncertainty. It represents cause and effects as nodes and connects them to form networks witha probability distribution. Bayesian Belief Networks are induced using data mining techniques. A 2D and 3D view are shown in Figure 3, providing the operator with a view of the causal relationships. Within the telecommunications domain, it is hoped that the application of the system will ultimately assist in 'intelligent' fault management.

\section{Design summary}

It was a requirement that the topology view be three dimensional to provide a better context view of the environment. Another requirement was that this environment must be dynamic real-time, for instance a network element must change color code as soon as its condition changes. This poses a challenge since the obvious approach - VRML doesn ot provide the necessary dynamic nature to achieve this. Ass uch the VRML solution lies in being able to rewrite a VRML script approximately every second tor efiect the current status of the network This would be programmed in Java.

\section{1) Java 3D API}

Initially the 'Java 3D API' was investigated as a possible means for visualizing the network view. The Java 3D API's scene graph-based programming model provides a mechanism for representing and rendering potentially complex 3D environments. It was hoped that the "Java 3D API' would have been an easier option, than using Java to write a VRML file. The idea was that the application could run as a single program file, rather than having to create a separate file. Howevert his became impractical, as the 'Java 3D API' was a lot more complicated to code, than VRML, with the programmer required to code the navigational controls, as wella s the three dimensionals cenes.

\section{2) VRML}

It was decided that the Virtual Reality Modelling Language (VRML) wouldb e used to publish the three dimensional scenes. VRML is a standard for the interchange of 3D data ont he World Wide Web. The widespread acceptance of VRML makes it a natural choice fors toring and sharing 3D geometry as output from a visualization package.

The VRML views are displayed using Cosmo Player. The player provides navigational tools, which allows the user to navigate through the network topology view. Cosmo Player has two sets of controls: Movement controls to move around in 3D worlds, and Examine controls to examine objects in a 3D world

\section{Implementation summary}

The network topology view itself consists of a split screen comprising a VRML canvas area (Cosmo Player), which allows for plotting the network visualization, and a text information area, where the requested color code and optionalv iews are listed (Figure 4).

The tool was designed to show the alarms, which were occurring on a selected network element (Local View), these files are created at the same time as the VRML view, representing the snapshot of the currents tatus of the network. eXtensible Markup Language (XML) and eXstensible Style Language (XSL) were usedt oi mplement the local views (Figure 5).

\section{CONCLUSION}

This work has produced a useful fault management visualization prototype to assist in exploring how the perceptual abilities and expertise of the operator can be utilized to rapidly identify a fault. It is also useful for making the data mining process more user-centric. To achieve discovered knowledige from data requires "interruption and evaluation", the human element, this tool facilitate this aim. The Gantt approach allows the event $\log$ 
to be rapidly and concisely visualized providing a fuller picture of what is occurring than scanning through text details of events raised.

With the aim of increasing the user-centric nature of the tool it is plannedt hat a more integrated tool is developed for instance to allow the user to pick thea reao $f$ data( events and/or timeframe) to be mined from historical event logs and store discovered patterns.

\section{ACKNOWLEDGEMENTS}

Michelle's placement was sponsored byt he University of Ulster within the Jigsaw project, which was funded by Nortel Networks (Northern Ireland) and IRTU (ITS Startl 87).

\section{REFERENCES}

[1] M. Klemettinen, 1999, A Knowledge Discovery Methodology for Telecommunication Network Alarm Databases, PhD Thesis, University of Helsinki, Finland. [2]G . Jackobson, M.D. Weissman, 1993, Alarm correlation, IEEE Network, 7(6), pp52-59.

[3] McBride, S., Sterritt, R, Curran, E.P., Adamson, K. and Shapcott, C.M., Maypole: Visualizing Contingency Tables, International Conference on Artificial Intelligence, Las Vegas, USA, pp823-829, 2000.

[4]K .E. Burn-Thomton, Using Virtual Reality Data Mining for Network Management; I CEIS, Portugal, July 2001.

[5] K.E. Bum-Thornton, "Virtual Reality Data Mining: A Future Technology of promise?', Proc. VR World Congress, Brussels, 5-7 July 1999

[6] K. Hatonen, M. Klemettinen, H. Mannila, P. Ronkainen, H.Toivonen, 1996, Knowledge Discovery from Telecommunication NetworkA larm Databases, Proc. 12th Int. Conf. on Data Engineering (ICDE'96), pp.115-122.

[7] ILog, ILogRules White Paper, 1998.

[8] RA. Becker, S.G. Eick, E.O. Miller, A.R. Wilks, Dynamic Graphics for Network Visaulization, IEEE CHI, pp93-96, 1990.

[9] C.Farrell, M. Schulze, S. Pleitner, M. Songerwala, Network Monitoring and Visualisation, Internetworkinng: Research and Experience, vol. 6, pp167-184, 1995

[10] R.A. Becker, S.G. Eick, A.R. Wilks, Visaulizing Network Data, IEEE Trans. Visualization and Graphics, Vol. 1 No. 1, March, pp16-28, 1995.

[11] M. crossley, N.J. Davies, R.J. Tayloe-Hendry, A.J. McGraph, Three-dimensional Internet Developments, BT Technol. J., Voll 5, No. 2, April, pp179-193, 1997.

[12] W. Buntine, "A Guide tot he Literature onL caming Probabilistic Networks from Data", IEEE Transactions on Knowledgea nd Data Engineering, Vol. 8, No. 2, pp.195$210,1996$. 


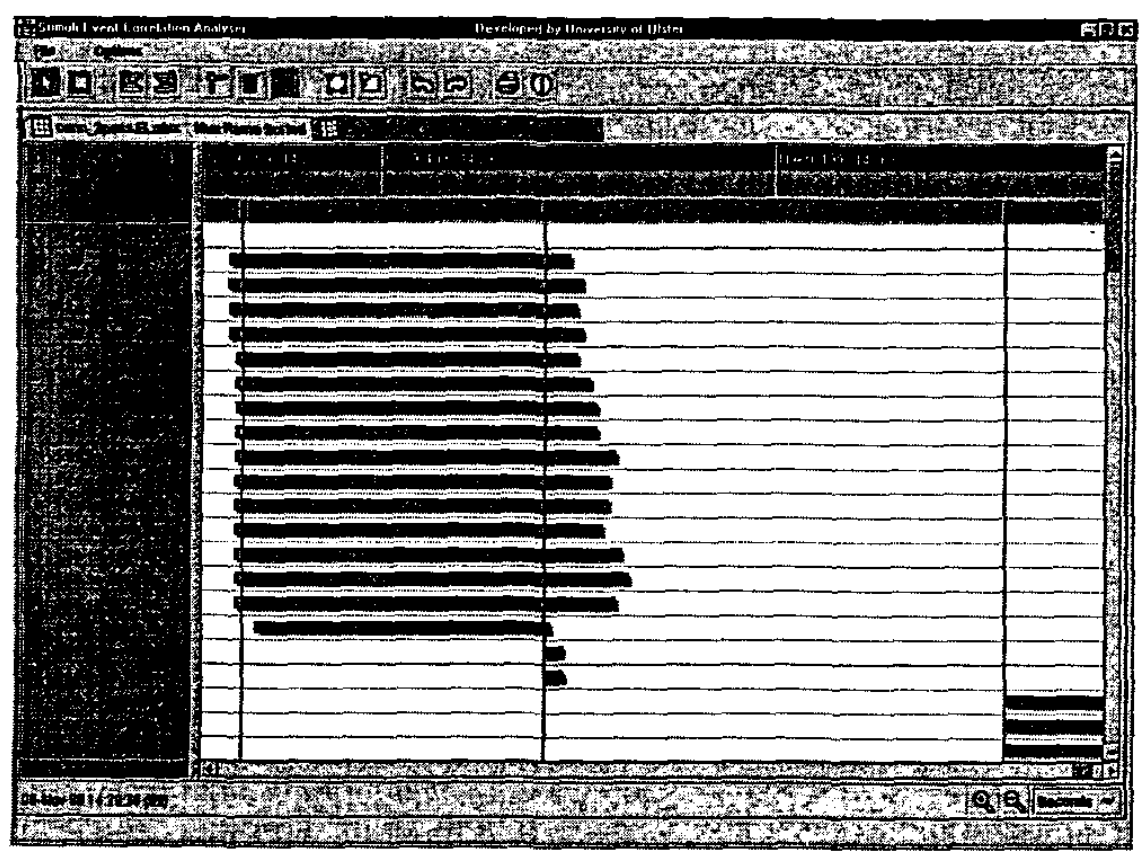

Figure 1 Fault Management Event Log displayed as a Gantt chart



(b)
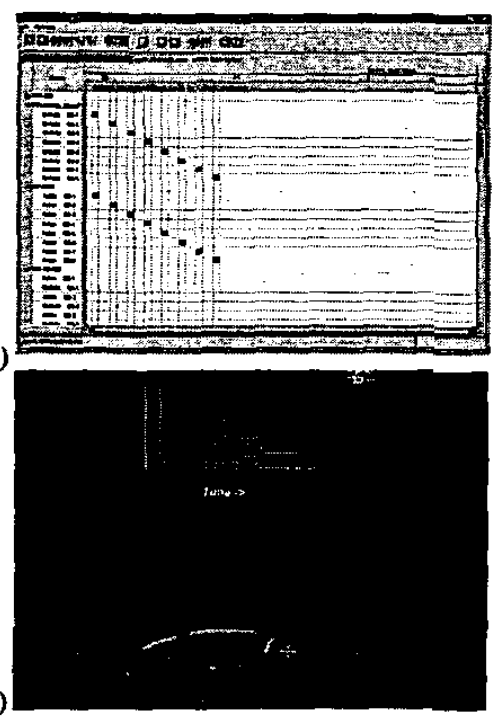

Figure 2 Providing a Context in viewing the alarm events against other network events 

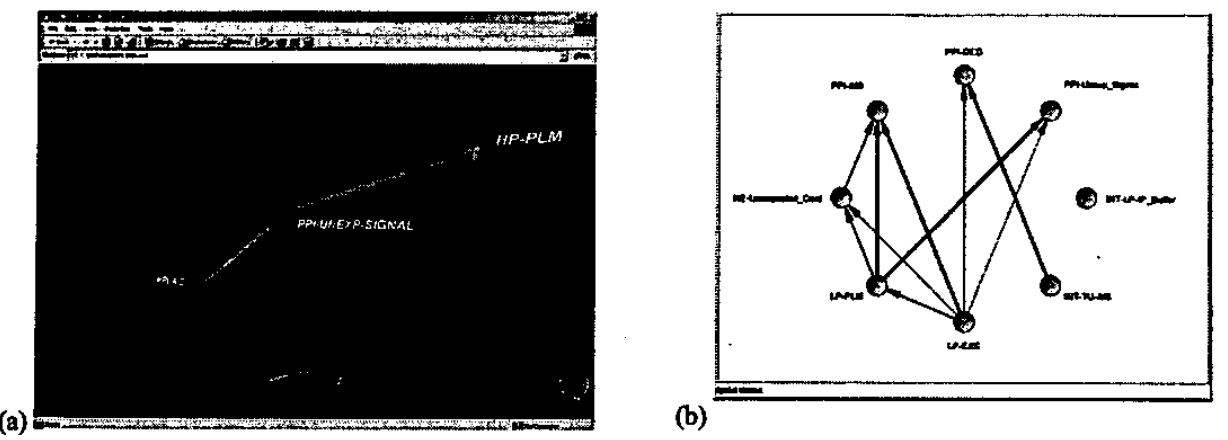

(b)

Figure 3 Providing a Context in viewing the data mined BBN

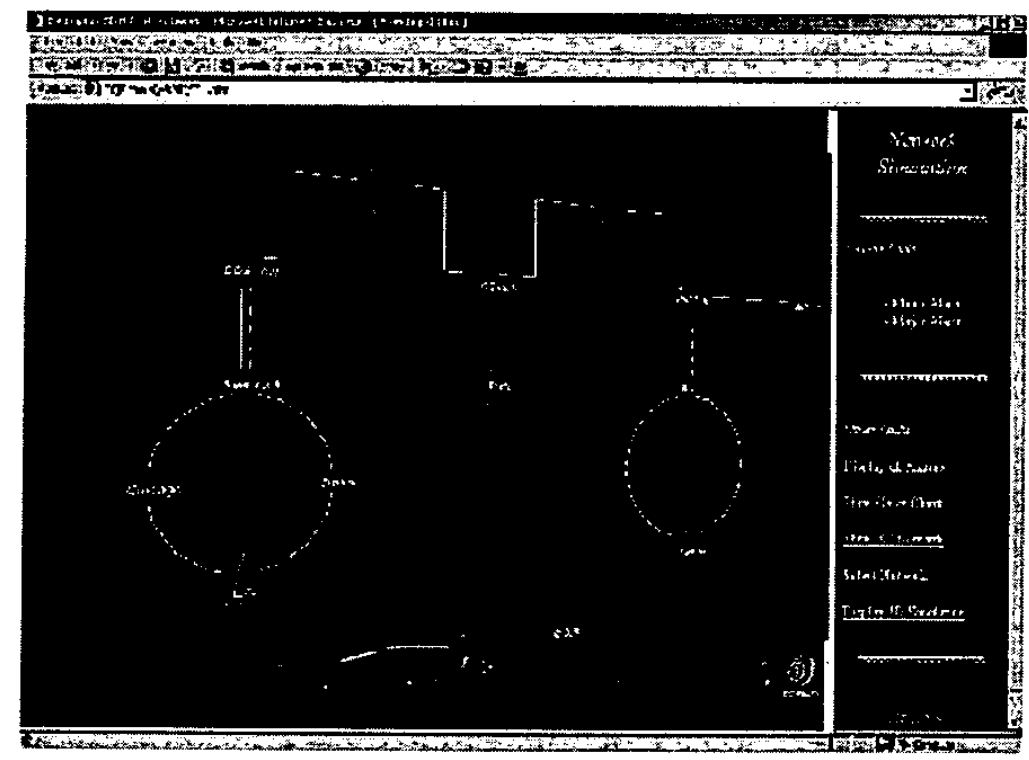

Figure 4 Topology view

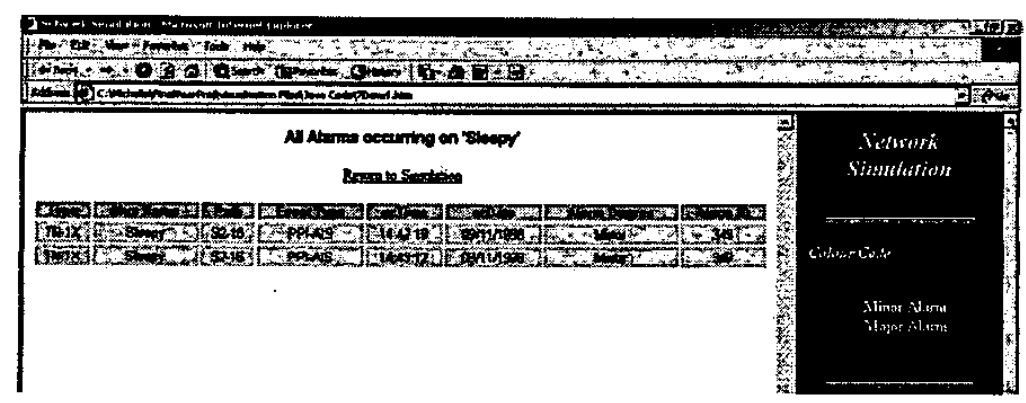

Figure 5 Local view of Network Element 